\title{
Reserva de Floresta Urbana (FURB) Mata do Passarinho: práticas ambientais e modo de gestão
}

\author{
Urban Forest Reserve Passarinho Forest: \\ environmental practices and management mode
}

\author{
Anderson José da Silva Fonseca ${ }^{1}$ \\ Helena Paula de Barros Silva ${ }^{2}$
}

\begin{abstract}
Resumo
A Reserva de Floresta Urbana-FURB Mata do Passarinho, faz parte de uma nova categoria do grupo das unidades de conservação de uso sustentável do Sistema Estadual de Unidades de Conservação do Estado de Pernambuco- SEUC, onde garantir a participação das comunidades locais no processo de gestão e conservação da natureza foi uma das principais finalidades dessa recategorização. A pesquisa teve como objetivo verificar, através de pesquisas in loco, se o modo de gestão da FURB Mata do Passarinho está de acordo com as leis que instituem o SEUC, na parceria entre órgão gestor e os interesses da sociedade. A metodologia consistiu na análise bibliográfica e entrevista com os gestores das UC. Os resultados indicaram que a lei afirma o compromisso da reserva em ser um espaço de interação sociedade e natureza, onde são desenvolvidas atividades de educação ambiental, entretanto, foi verificado um cenário de gestão pública ineficiente, onde faltam investimentos do setor público e o pouco contingente de servidores para atuarem como gestores, não só da categoria em estudo, mas de todas outras UC estado de Pernambuco.

Palavras-chave: Unidade de Conservação, Reserva de Floresta Urbana, Mata Atlântica, SEUC.
\end{abstract}

\begin{abstract}
The Urban Forest Reserve - FURB Mata do Passarinho, is part of a new category of the group of sustainable use of protected areas of the State System of Conservation Units of the Pernambuco' State - SEUC, which ensure the participation of local communities in the process of management and nature conservation was one of the main purposes of this re-categorization. The research aimed to verify through research in loco if the management mode of FURB Passarinho Forest is in accordance with the laws establishing the SEUC based on partnership between the managing agency and the interests of society. The methodology consisted of literature and interview analysis with the managers of Conservation Units (CU). The results indicated that the law states the commitment of the reservation to be a space for interaction society and nature, where environmental education activities are developed, however, an inefficient public management scenario where lack of investment in the public sector
\end{abstract}

\footnotetext{
${ }_{1}^{1}$ Universidade Federal de Pernambuco. Recife, Pernambuco, Brasil. anderson.profgeo86@gmail.com

${ }^{2}$ Universidade de Pernambuco. Nazaré da Mata, Perambuco, Brasil. helena.silva@upe.br

Artigo recebido em: 03/03/2017. Aceito para publicação em: 29/11/2018.
} 
and the little contingent of people was found servers to act as managers, not only of the category in question but all other (CUs)state of Pernambuco.

Keywords: Conservation Unit, Urban Forest Reserve, Passarinho Forest, SEUC

\section{Introdução}

As Unidades de Conservação (UCs)do Estado de Pernambuco foram instituídas pela lei estadual $n^{\circ} 13.787$ de 08 de junho de 2009, que criou o Sistema Estadual de Unidades de Conservação da Natureza - SEUC. Dentre as variadas classificações dos grupos das unidades de conservação do SEUC, estão presentes as Reservas de Florestas Urbanas - FUBR que surgem a partir de uma necessidade de recategorização das Estações Ecológicas do estado de Pernambuco onde oito delas tornaram-se FURB a partir da lei $n^{0} 14.324$ de 02 de junho de 2011.

A Agência Estadual de Meio Ambiente $(\mathrm{CPRH})$, órgão ambiental do estado de Pernambuco, tendo a sua autonomia em criar unidades de conservação baseada no que está disposto no artigo $6^{\circ}$, inciso III da lei $\mathrm{n}^{\circ}$ 9.985 de 18 de julho de 2000 do Sistema Nacional de Unidades de Conservação da Natureza - SNUC, criou essa nova categoria incluindo no grupo das unidades de conservação de uso sustentável as FURB, tendo em vista reconhecer os fragmentos florestais existentes em áreas urbanas como espaços para integrar a comunidade local no processo de conservação da natureza.

De acordo com o artigo 20 do SEUC e seus parágrafos seguintes, as FURB detêm de atributos ambientais significativos e que tem como objetivos prestar serviços ambientais, como amenização do clima, disponibilidade de água, redução de poluição atmosférica, dentre outros, e ainda poderão ser desenvolvidas atividades de educação ambiental, recreação e lazer envolvendo assim as comunidades locais no processo de gestão da unidade. 
Porém, segundo o SEUC (2009); Santos et al, (2015), não é somente criando unidades de conservação que vai garantir que os seus objetivos sejam alcançados, mas é promovendo a integração entre a sociedade e natureza no processo de conservação dos ambientes naturais. Para que essa relação seja realmente efetivada é necessário que a unidade de conservação possua o seu plano de manejo bem definido levando em consideração os interesses das comunidades locais.

A FURB Mata do Passarinho é atualmente a única Reserva de Floresta Urbana do estado de Pernambuco que possui um plano de manejo definido, elaborado no ano de 2013 pela Secretaria de Meio Ambiente e Sustentabilidade do Estado de Pernambuco e Prefeitura Municipal de Olinda.

Sendo assim, este artigo objetiva-se analisar como se procede a participação das comunidades no processo de gestão da FURB Mata do Passarinho junto aos órgãos gestores.

Tal análise se deu através de entrevistas com os gestores da UC em estudo e levantamento bibliográfico para que por fim pudesse ser feita uma análise entre o que está disposto no plano de manejo com a atual realidade da gestão.

\section{As Reservas de Florestas Urbanas (Furb) de Pernambuco}

As Reservas de Florestas Urbanas fazem parte do grupo das Unidades de Conservação de uso sustentável e, segundo o artigo primeiro e vigésimo da Lei Estadual 13.787, de 08 de junho de 2009, que institui o SEUC, configura:

[...] reconhecer os fragmentos de florestas existentes em áreas urbanas como elementos fundamentais para a qualidade de vida nas cidades, (...) além de belas paisagens e espaços privilegiados para o lazer, cultura e turismo, integrando as populações urbanas ao processo de conservação destes fragmentos (LEI ESTADUAL $\mathrm{N}^{\circ}$ 13.787 DE 08 DE JUNHO DE 2009). 
De acordo com o Art. 20 desta mesma lei, as FURB são caracterizadas como uma área remanescente de ecossistemas com predominância de espécies nativas, localizada no perímetro urbano, constituídas por área de domínio público ou privado que, apesar de pressões existentes em seu entorno, ainda detêm atributos ambientais significativos.

Todas as Reservas de Floresta Urbana eram antes classificadas como Reservas Ecológicas da Região Metropolitana do Recife, criadas a partir da Lei Estadual n ${ }^{\circ} 9.989$ de 13 de janeiro de 1987. Após vinte e quatro anos, a $\mathrm{CPRH}$, objetivando enquadrar as UC que não estavam amparadas pelo Sistema Nacional de Unidades de Conservação (SNUC) e nem pelo Sistema Estadual de Unidades de Conservação (SEUC), extinguiu a categoria de Reserva Ecológica e recategorizou oito delas para FURB.

O SNUC não prevê como classificação ou subclassificação as Reservas Ecológicas, ficando estas apenas respaldadas pela Lei Estadual No 11.206/95 a qual institui a Política Florestal de Pernambuco, já criada desde 1995. No ano de 2009, o Governo de Pernambuco instituiu o SEUC através da Lei ${ }^{\circ}$ 13.787/09, onde também não incluía a categoria de Reservas Ecológicas.

Para mudar este quadro legal e fazer com que as Reservas Ecológicas fizessem parte dos sistemas de unidades de conservação já criados, a Secretaria de Meio Ambiente e Sustentabilidade de Pernambuco, por meio da Assembleia Legislativa do Estado, revogou o capítulo V da lei da Política Florestal de Pernambuco e, em 02 de junho de 2011, foi sancionada a lei $\mathrm{n}^{0}$ 14.324/2011 readequando o as antigas Reservas Ecológicas ao SEUC, a qual dispõe no seu artigo $1^{\circ}$, inciso III, a recategorização de oito Reservas Ecológicas para Reservas de Florestas Urbanas - FURB.

As Reservas Ecológicas recategorizadas foram: Mata de São Bento Abreu e Lima (PE), Mata de Camaçari- Cabo de Santo Agostinho (PE), Mata de Jangadinha e Mata de Manassú - Jaboatão dos Guararapes (PE), Mata do Passarinho - Olinda (PE), Mata de Jaguarana e Mata do Janga Paulista (PE) e a Mata de Dois Unidos - Recife (PE). 
De acordo com que dispõe no SEUC, a norma geral que rege a categoria deixa definido que nas Reservas de Floresta Urbana poderão ser desenvolvidas atividades de educação ambiental, recreação e lazer para a inserção das comunidades no processo de conservação da natureza.

A denominação Reserva de Florestas Urbanas, assim como já foi citado, é de exclusividade do SEUC do Estado de Pernambuco. Localizadas dentro da área urbana da Região Metropolitana do Recife, as FURB tem como objetivo principal, segundo o parágrafo primeiro, Art. 20 do SEUC:

[...] prestar serviços ambientais às cidades tais como: proteção de nascentes e disponibilidade de água, amenização do clima, manutenção e proteção do solo contra erosão, controle de enchentes, redução da poluição atmosférica, influenciando direta ou indiretamente a qualidade de vida urbana (Art. 20, § 1, Lei Estadual $n^{\circ} 13.787$ de 08 de junho de 2009).

No processo de gestão da Reserva de Floresta Urbana, de acordo com o artigo $20, \S 3^{\circ}$ da lei 13.787 , de 08 de junho de 2009 , deverá ser priorizado o envolvimento da comunidade local, incorporando na gestão da unidade a valorização dos serviços ambientais prestados, estabelecendo, assim, uma interação entre a floresta e a comunidade a partir das utilidades e necessidades de cada uma delas. Para viabilizar a gestão da unidade, de acordo com o artigo $20, \S 4^{\circ}$ do SEUC, poderá ser estabelecida parceria entre o órgão gestor e o proprietário da terra, quando esta for de propriedade privada.

Sendo assim, as FURB são espaços que podem promover o envolvimento da comunidade local, incorporando na gestão da unidade a valorização dos serviços ambientais prestados, estabelecendo assim uma interação entre a floresta e a comunidade a partir das utilidades e necessidades de cada uma delas.

Segundo Christofoletti (2003), viabilizando o envolvimento da comunidade no trabalho e na utilização dos recursos naturais de forma a tirar deles o proveito sem comprometer a disponibilidade destes recursos para as gerações futuras. 
O plano de manejo, documento criado pelo órgão ambiental competente, deve ser elaborado também em conjunto com as secretarias municipais de meio ambiente a fim de promover o envolvimento das comunidades locais para que haja a efetiva participação de todos no processo de elaboração do documento.

O plano de manejo, documento criado pelo órgão ambiental competente, deve ser elaborado também em conjunto com as secretarias municipais de meio ambiente a fim de promover o envolvimento das comunidades locais para que haja a efetiva participação de todos no processo de elaboração do documento.

O Art. 33 da lei que institui o Sistema Estadual de Unidades de Conservação dispõe as diretrizes para a criação do plano de manejo e dá outras competências, tais como:

\footnotetext{
Art. 33. Todas as unidades de conservação devem dispor de um Plano de Manejo, (...)

$\S 1^{\circ} \mathrm{O}$ Plano de Manejo deverá contemplar medidas para promover a integração econômica e social das comunidades vizinhas à unidade conservação.

$\S 2^{\circ} \mathrm{Na}$ elaboração, atualização e implementação do Plano de Manejo será assegurada a ampla participação da população local e da sociedade civil.

Art. 34. São proibidas, nas unidades de conservação, quaisquer alterações, atividades ou modalidades de utilização em desacordo com os seus objetivos, com o seu Plano de Manejo e seus regulamentos (LEI N ${ }^{\circ}$ 13.787, DE 08 DE JUNHO DE 2009).
}

As atividades desenvolvidas nas UC devem seguir as diretrizes de um plano de manejo e que este deve envolver a participação da população local e da sociedade civil. A necessidade de agregar a participação social no planejamento do documento que rege as atividades da UC é atender aos interesses da comunidade local agregado aos interesses políticos e de gestão das unidades de conservação.

As UC precisam ser locais onde a coletividade seja o fator desencadeante para a conservação da natureza, promovendo a participação das comunidades na conservação destes ambientes, resgatando saberes 
tradicionais das populações que muitas vezes sempre viveram em contato direto com a natureza e souberam sempre preservá-la (DIEGUES,1996).

A FURB serve também de lugar que estimule programas e recursos para atingir o desenvolvimento econômico, uso adequado dos recursos naturais, melhoria social e bem-estar das comunidades para que sejam atingidos os objetivos destas unidades de conservação.

Sendo assim, as FRUB da Região Metropolitana do Recife são espaços que, além de promover a coletividade, exercem um papel ecológico fundamental, como a manutenção do clima nas áreas próximas à UC, onde se percebe temperaturas mais amenas, proteção do solo contra a erosão, observado principalmente nas áreas de borda, controle de enchentes, assegurando ao solo a permeabilidade da água e a redução dos níveis de poluição gerada pelas cidades, além de serem locais que conservam uma biodiversidade singular da Mata Atlântica.

\section{Gestão da FURB Mata do Passarinho}

A FURB Passarinho está localizada no município de Olinda do estado de Pernambuco. Segundo seu plano de manejo, a UC possui uma área total de 13,36ha, abrange um percentual aproximado de 0,31\% da área total do município. Da área total da Mata do Passarinho, 11,60ha pertencem à prefeitura municipal de Olinda e 1,76ha são correspondentes à área privada.

A Mata do Passarinho está inserida no bairro de Passarinho e é circundada pelos bairros de Alto da Bondade, Caixa d'água, Águas Compridas, Córrego dos Carneiros e Córrego do Abacaxi, todos pertencentes ao município de Olinda. De acordo com dados de seu plano de manejo, a FURB Mata do Passarinho (mapa 1) é o maior remanescente de Floresta Ombrófila Mista IBGE (2012) do município de Olinda.

O mapa abaixo de organização dos autores foi feito com base nos dados cartográficos do Sistema de Informações Geoambientais de 
Pernambuco - Caburé (SIG Caburé) da CPRH que ilustra a localização da unidade de conservação em relação ao perímetro do município de Olinda.

Mapa 1 - Localização da FURB Mata do Passarinho no município de Olinda (PE).

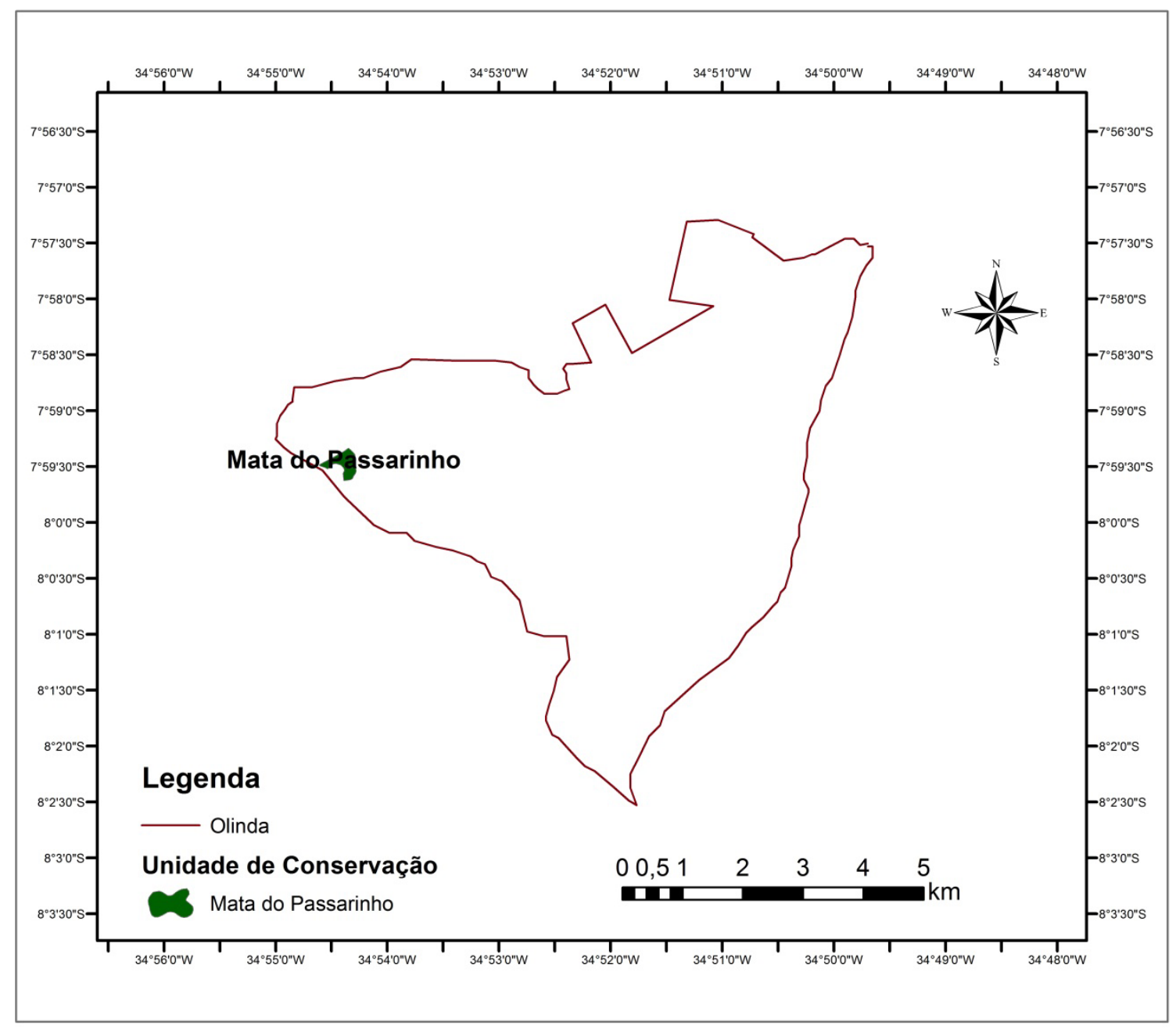

Fonte: Org.: do Autor, 2017.

A FURB Mata do Passarinho é atualmente administrada pela Prefeitura de Olinda, ficando ao seu cargo todo processo de gestão da UC. A $\mathrm{CPRH}$ entra como apoio nas demandas de planejamento ambiental, da unidade de conservação.

A necessidade de criar o plano de manejo partiu da Prefeitura Municipal de Olinda, pois, de todas as FURB a Mata do Passarinho é a 
única que possui ações que efetivamente envolvem a comunidade do entorno, como educação ambiental, que mobilizam escolas (públicas e privadas), universidades, comunidade do entorno e toda sociedade interessada em conhecer a unidade de conservação.

Após a implementação do plano de manejo, foram definidas algumas diretrizes sobre o uso e ocupação do solo na área da UC, onde não é permitida a construção de edificações em áreas de preservação ecológica e, também a lei orgânica do município de Olinda, de 03 de abril de 1990, em seu artigo 128, parágrafo $1^{\circ}$, inciso V, define a Mata do Passarinho como uma das seis áreas de proteção especial para assegurar a preservação dos aspectos históricos, culturais e ambientais do município.

Entretanto, um grande problema encontrado não só na Mata do Passarinho, mas em todas as FURB é a derrubada irregular de árvores para a construção civil. Ademais, a fiscalização estadual que deveria ser feita pela $\mathrm{CPRH}$ em parceria com a Companhia Independente de Policiamento do Meio Ambiente - CIPOMA, ainda se apresenta bastante incipiente. Atualmente, fica na responsabilidade da Secretaria de Segurança Pública de Olinda (GMO) a fiscalização e segurança da UC.

Foi realizada uma entrevista em 2014 com 2 (dois) dos 8 (oito) servidores públicos pertencentes ao quadro da Agência Estadual de Meio Ambiente (CPRH), lotados na Unidade de Gestão de Unidades de Conservação (UGUC), responsáveis, até o momento em que estava sendo feita a pesquisa para este artigo, pelas unidades de conservação do estado de Pernambuco.

Foi levantado um quantitativo de 84 (oitenta e quatro) unidades de conservação estaduais em Pernambuco, sendo 40 (quarenta) de Proteção Integral 44 (quarenta e quatro) de Uso Sustentável, além de 15 Reservas Particulares do Patrimônio Natural (RPPN). Dentre deste quantitativo, 8 são Reserva de Floresta Urbana, disseminadas por toda Região Metropolitana do Recife 
De acordo com informações do Plano de Manejo da Mata do Passarinho (2013), a gestão da FURB deve ser compartilhada entre o governo do estado de Pernambuco, de responsabilidade da CPRH e a prefeitura municipal de onde a floresta está inserida. Assim, a UC passa a ser mantida, tanto pela prefeitura como pelo governo do estado.

Em entrevista com gestores da Mata do Passarinho, foi informado que a UC encontra-se exclusivamente a cargo da Prefeitura Municipal de Olinda, através da Secretaria Executiva de Planejamento Ambiental. Tendo em vista que existem dificuldades no gerenciamento em se tratando de recursos financeiros e humanos.

Foi informado também que a Mata do Passarinho, em relação às outras FURB, era a única UC que desde antes de sua recategorização, quando ainda era uma Reserva Ecológica, já possuia uma gestão efetiva do município. Assim, as atividades foram reativadas, cumprindo os objetivos expostos no Plano de Manejo vigente, onde há uma implementação de melhorias para a UC.

A educação ambiental (figura 1) é o foco das ações desenvolvidas na FURB Mata do Passarinho. De acordo com o que está disposto no quadro de Programas de Atividades para a Gestão descrito em seu plano de manejo há dois eixos temáticos: o de educação ambiental e o de comunicação e integração com a comunidade. No primeiro eixo, a Reserva tem o seu planejamento voltado para o desenvolvimento de atividades e projetos envolvendo a comunidade do entorno, escolas públicas e privadas, universidades e toda sociedade civil interessada, relacionando todo contexto da importância das áreas verdes das UC, assim como, na valorização e sensibilização da sua conservação e biodiversidade. 
Figura 1 - Atividade de educação ambiental na Mata do Passarinho. Circuito Ambiental realizado por técnicos da CPRH com alunos da escola da Rede Municipal de Olinda.

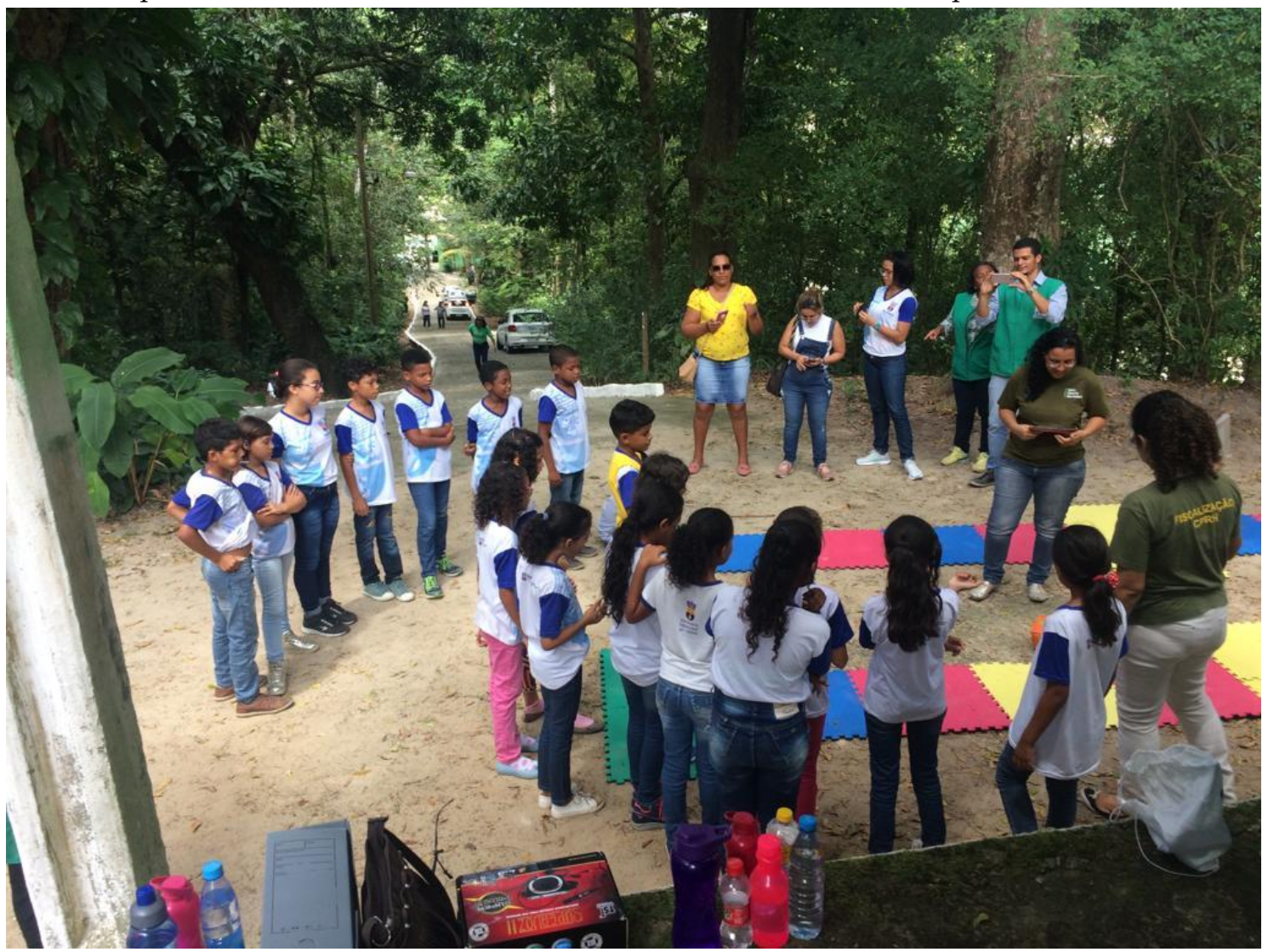

Fonte: PMO, 2018.

Assim, conforme Dias (2003) sobre a inserção da escola em atividades de educação ambiental, afirma que:

As atividades de Educação Ambiental devem ser o centro do programa porquanto permitem, aos alunos, oportunidades de desenvolver uma sensibilização a respeito dos seus problemas ambientais e buscar formas alternativas de soluções, conduzindo pesquisas no ambiente urbano, relacionando fatores psicossociais e históricos com fatores políticos, éticos e estéticos (DIAS, 2003, p. 217).

A FURB Mata do Passarinho surge como uma alternativa de espaço para o desenvolvimento de atividades que busquem a sensibilização para a conservação da fauna e flora. Esta é uma tarefa que o educador e profissionais da área, juntamente com parcerias público-privadas, devem desenvolver ações que levem à prática da Educação Ambiental. 
Além de atividades que envolvam escolas, a mata oferece também trilhas que são realizadas no interior da mata para que a pessoa possa entrar em contato diretamente com a fauna e a flora da unidade de conservação. As trilhas são sempre realizadas e monitoradas por um técnico responsável.

A soltura de animais silvestres é outra atividade presente na UC. A Prefeitura Municipal de Olinda, em parceria com o Centro de Triagem de Animais Silvestres do Estado de Pernambuco (Cetas), recolhe alguns animais que já estão aptos a voltar ao habtat natural e realiza uma campanha que move toda sociedade civil interessada para participar deste evento.

Outras atividades que são desenvolvidas pela gestão da UC, é a descentralização das ações de educação ambiental em escolas e universidades, com o objetivo de intensificar a divulgação da FURB Mata do Passarinho para toda sociedade. Esta divulgação se dá por meio de palestras e oficinas mostrando a importância da conservação da biodiversidade local, já que é considerada o único remanescente de Mata Atlântica do município de Olinda.

Há parcerias com a secretaria de educação que é responsável pela liberação, mobilização e transporte das escolas municipais de Olinda e a Associação Pernambucana de Apicultores e Meliponicultores (APIME), responsável pela manutenção das colmeias de abelhas nativas da Mata Atlântica sem ferrão.

A atividade de Educação Ambiental com a APIME (figura 2) tem como objetivo a sensibilização socioambiental da conservação das espécies e principalmente na garantia da reprodução e renovação do ciclo de vida das florestas através da polinização. Segundo a atual gerência da UC estão sendo feitas novas parcerias para o monitoramento da fauna e flora. 
Figura 2 - Atividade de educação ambiental realizada com agentes da Associação Pernambucana de Apicultores e Meliponicultores (APIME) mostrando a importância do cultivo de mel com abelhas sem ferrão nativas da Mata Atlântica.

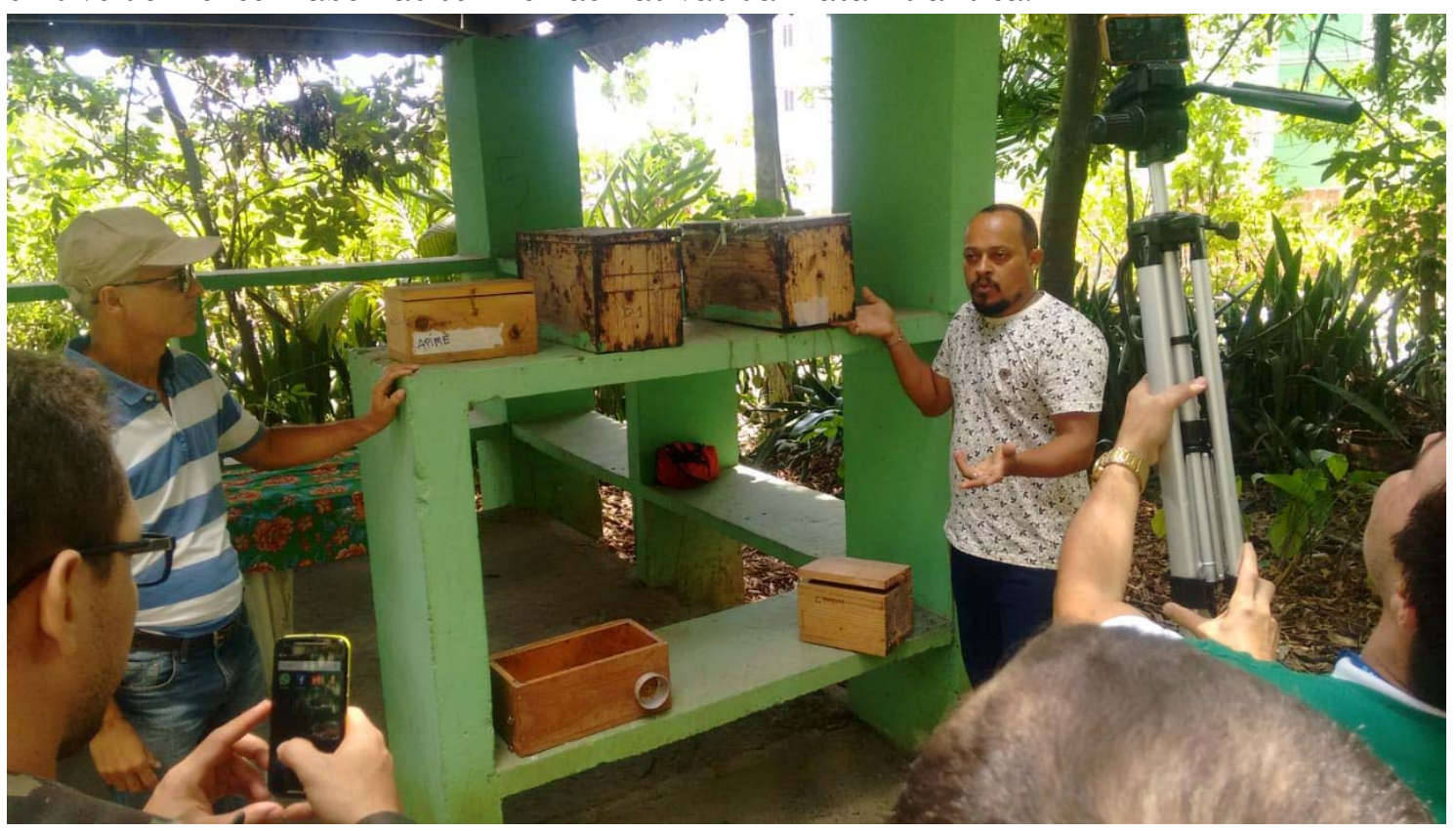

Fonte: PMO, 2018.

\section{Considerações Finais}

Até a conclusão desta pesquisa, a FURB Mata do Passarinho continua sendo a únida unidade de conservação (UC), dentro da sua categoria, que possui um plano de manejo definido e elaborado com ampla participação social. Desde a sua criação, a Mata do Passarinho passou por diversos problemas, como invasões e abandono, tanto por parte dos órgãos públicos quanto da própria sociedade civil.

A sua recategorização de Reserva Ecológica para Reserva de Floresta Urbana deu-se através de seu atual estado de conservação e localização e, por estar situada totalmente em perímetro urbano, foi necessário criar uma categoria que pudesse englobar todas estas unidades de conservação que se encontravam nesta situação.

Dentre todas as outras sete FURB, a Mata do Passarinho é a única que atualmente possui sede administrativa, espaço para realização de 
atividades educacionais, trilhas e gestão, ficando a cargo da Prefeitura de Olinda toda administração da unidade de conservação.

O Governo do Estado de Pernambuco, junto com a Agência Estadual de Meio Ambiente $(\mathrm{CPRH})$ têm se mostrado incipiente no tocante a gestão e administração das FURB, alegando falta de recursos financeiros e de capital humano. As leis que instituem as unidadas de conservação no estado de Pernambuco são claras e eficientes, o que falta é uma gestão comprometida com as questões ambientais, tanto a nível estadual, quanto municipal.

A Mata do Passarinho merece seu lugar de destaque em relação às outras FURB do estado de Pernambuco, pois é a única UC que consegue atingir uma boa parte de seus objetivos, como a realização de atividades educativas, palestras, trilhas, habitat de espécies silvestres nativas de fauna e flora, conservação do solo e da biodiversidade.

Assim, a Mata do Passarinho, mesmo com todos os problemas de gestão apresentados, serve como exemplo de um espaço socioambiental que promove o envolvimento da sociedade no processo de conservação da natureza.

\section{Agradecimentos}

A Agência Estadual de Meio Ambiente (CPRH), especialmente aos gestores entrevistados da Unidade de Gestão de Unidades de Conservação (UGUC), pelas informações dadas e acolhimento.

A Prefeitura Municipal de Olinda (PMO), especialmente a gestão da Reserva de Floresta Urbana Mata do Passarinho e a Secretaria Executiva de Planejamento Ambiental. 


\section{Referências}

BRASIL - .Lei Federal n ${ }^{\circ}$ 9.985, de 18 de julho de 2000. Institui o Sistema Nacional de Unidades de Conservação da Natureza - SNUC e dá outras providências. Brasília: DOU 19/07/de julho de 2000.

CHRISTOFOLLETI, Antônio. Modelagem de Sistemas Ambientais. Ed. $3^{\text {a }}$. São Paulo: Edgard Blücher, 2003.

CPRH - AGÊNCIA ESTADUAL DE MEIO AMBIENTE. Plano de Manejo da Reserva de Passarinho é exemplo nacional. Disponível em: <http://www.cprh.pe.gov.br/home/41550\%3B40011\%3B10\%3B2146\%3B2900.asp>. Acesso em: 03 de março de 2017.

CPRH - AGÊNCIA ESTADUAL DE MEIO AMBIENTE. Sistema de Informações Geoambientais de Pernambuco - SIG Caburé. Disponível em: $<$ http://sigcabure.cprh.pe.gov.br/maps.jsp> . Acesso em: 01/03/ de março de 2017.

DIAS, Genebaldo Freire. Educação Ambiental: princípios e práticas. Ed. 8a. São Paulo: Gaia, 2003.

DIEGUES, Antônio Carlos. O Mito Moderno da Natureza Intocada. São Paulo: Hucitec, 1996.

PERNAMBUCO. Lei Estadual $n^{\circ} 11.206$ de 31 de março de 1995. Dispõe sobre a Política Florestal do Estado de Pernambuco e dá outras providências. Recife: DOE 31/03/ de março de 1995.

PERNAMBUCO. Lei Estadual $\mathrm{n}^{0}$ 13.787, de 08 de junho de 2009. Institui o Sistema Estadual de Unidades de Conservação da Natureza - SEUC, no âmbito do estado de Pernambuco e dá outras providências. Recife: DOE 09/06/ de junho de 2009.

PERNAMBUCO. Lei Estadual n 14.324 de 02 de junho de 2011. Categoriza as Reservas Ecológicas da Região Metropolitana do Recife e dá outras providências. Recife: DOE 02 de junho de 2011.

SANTOS, Natália Britto dos; VILHENA, Cecília Fernandes de. Repensar é Preciso: A experiência do grupo de trabalho sobre criação, implantação e gestão das unidades de conservação estaduais de Minas Gerais. In: Anais do VIII CBUC. Curitiba, 21 de Set., 2015.

SECRETARIA DE MEIO AMBIENTE E SUSTENTABILIDADE; CPRH - AGENNCIA ESTADUAL DE MEIO AMBIENTE. Plano de Manejo da Reserva de Floresta Urbana - FURB Mata do Passarinho. Recife: A Secretaria, 2013. 